\section{The buck stops with government}

SIR - The recent debate on the closure of several major research groups by the MRC has mainly focused on the way in which the council has taken these decisions. I have recently been on one of the MRC research boards, and from 1980 to 1990 I chaired one of the MRC committees that rank applications for project grants. From that experience, I believe that much of the criticism should instead have been aimed at the government.

Although I have sometimes disagreed with the priorities adopted by the recently formed MRC strategy committee, the government is responsible for putting the $\mathrm{MRC}$ in a position that forces it to make awful choices and to fund Britain's excellent medical research community inadequately. As a result, we have lost excellent science not only in a few high-profile MRC units, but also in laboratories deserving support through long-term programme grants or short-term project grants.

In many ways, the most depressing of these changes - both for the MRC committee members and their clients - is the striking decline in the funding of project grants. Although it is easy to focus public criticism on research council decisions to close major research enterprises, the recent across-the-board decimation of excellent project grant proposals has been a much less public 'death by a thousand cuts'.

The loss of project grants may in the long term have disastrous consequences for the whole UK research enterprise. Two things tend to be lost. First, many new and bright young scientists setting out on research careers - who hold the future of British science in their hands - fall at the first grant-seeking hurdle. Second, funding is disappearing for many of the more senior and still excellent academics who combine first-class research with increasingly heavy teaching and administrative roles in financially strapped universities - but whose research is on a scale too small or in a field too unfashionable for programme grant funding.

A year ago I took up these concerns in a letter to the prime minister. Her first response was to point out that there was really no problem, as MRC "in recent years" had funded about 80 per cent of $\alpha$-rated project grants - which was true for a couple of years in the mid-1980s and that new money made available in 1988-89 "should allow [MRC] to sustain or increase this level of support for grants". When I informed her that in the event only 55 per cent of the 1988-89 $\alpha$-rated grants were funded, a second letter from Downing Street told me that this fall "cannot be attributed to government". The MRC had been given more money and "it is for the MRC to deter- mine its own funding priorities".

During 1989-90, both the absolute number of project grant applications and committees increased substantially over 1988-89, but the number funded was essentially unchanged. The funding rate fell to 47 per cent of $\alpha$-rated proposals, little more than half of the 80 per cent that in September 1989 was deemed a desirable target by the prime minister.

The real problem appears to be that the UK government still believes that it can get first-rate research without first-rate investment. And the research councils, who act as the government's agents in distributing research funds, have failed to emphasize just how much of the good science they should be supporting is lost for lack of funds: too often they greet modest increases in funding with statements of public gratitude rather than with reminders of the problems that remain.

School of Biochemistry,

The University of Birmingham,

Edgbaston, Birmingham B15 2T, UK

SiR-In the news item 'Storm over funding policy' (Nature 348, 6; 1 November 1990 ) much prominence is given to criticisms of recent closures and cuts made by the MRC. There also was some suggestion that the strategy committee of the MRC council has acted in a way contrary to the normal practice of basing funding decisions on peer review. I would like to put forward a different view based on my experience as a past member of the MRC council and a member of the strategy committee from its inception until my retirement from the council earlier this year.

First, the MRC faces financial problems not of its own making. Quite simply, if there continues to be an annual gap between the increases in cost and the provision for salaries in the grant-in-aid, as there is in 1990-91, staff will need to be reduced by 6 per cent every year unless savings can be made elsewhere. Indeed, if this gap extends to all research costs, as it does, then the MRC will be forced to curtail more and more of its activities. In times of financial stress it is short-term support, like project grants, that can be most easily cut, and so the science that will suffer most is that carried out in universities and medical school laboratories. This is unacceptable because it destroys the research base for graduate student training in the universities with disastrous longer term effects.

The MRC council set up the strategy and to avoid what has happened in the past when urgent financial decisions were made administratively without much the number of grants rated by the grants committee to deal with these problems regard for scientific policy. The committee includes the chairman of the boards and two to three of the independent scientific members of the council. It is definitely not a group that can act independently of the boards; indeed, its structure ensures that decisions are based on proper scientific review. And, of course, all its decisions are subject to approval by the whole council. None of the recent decisions has been taken peremptorily; all are the outcome of the development of long-standing policy.

The council has not in any way abrogated the processes of peer review. Experts in a particular field can make assessments only within that field and different judgements are required for comparing work that ranges over different fields. As many prospective authors to your journal well know, passing technical referees even with flying colours does not guarantee appearance. Additional appraisals in wider fields are made by the council's boards, and the strategy committee was set up to pursue the same process at the most general level and to ensure that funding decisions are still subject to scientific policy and not made by accountants.

For all its much vaunted success peer review has a dark side. When money is flowing, it is marvellous because all it has to do is to exclude the extremes of lunacy and banality. As funds contract, there is not only greater and greater selection of the conservative and the proven successful, but this is accompanied by a growing tendency of applicants to cast their proposals in the same conservative mould. This threatens innovation, which is always risky, and affirmative action is needed by the MRC and other institutions to encourage new research and, if necessary, to override expert opinion. If, 40 years ago, the MRC had relied on the judgement of contemporary experts they would never have supported the infant science of molecular biology.

MRC Molecular Genetics Unit SYDNEY BRENNER Hills Road, Cambridge CB2 9QH, UK

\section{Verbal abuse?}

SIR - In a recent article (Nature 347, 225; 1990), John Maddox protested rather trenchantly (albeit parenthetically) to using the verb form of the noun "intuition". I, for one, intuit (from the Latin intuitus, past participle of the verb intueri) no good reason to prohibit (from the Latin prohibitus, past participle of the verb prohibere) such use, and I pray he does not edit (from the Latin editus, past participle of the verb edere) the life out of this riposte.

Cedars-Sinai Medical Center,

GEORGE A. DIAMOND

Los Angeles,

California 90048-1869, USA 